\title{
Development of Values of Tolerant Consciousness and Behavior of Students in a Multicultural Educational Space
}

\author{
Alsu Fatikhovna Sharafeeva \\ Guzaliya Zhevdyatovna Fahrutdinova \\ Dzhamilia Renatovna Nugmanova \\ Kazan (Volga Region) Federal University, Republic of Tatarstan, 420008, Kazan, \\ 18, Kremlyovskaya Street, Russian Federation
}

\section{Doi:10.5901/mjss.2015.v6n4s1p258}

\begin{abstract}
The article addresses the urgent problem of setting the stage for supporting the priority of values of tolerance in the educational space of higher educational institutions. The significance of this activity is associated with the sociocultural realities of Russia as a multicultural and multi-religious country, as well as with the needs of humanization of the educational process in accordance with the need of its reforming on the basis of personality and competency-based approaches. Specific psychological and pedagogical actions which should be taken to get the above mentioned results are set forth within the framework of the proposed methodology, which involves diagnostics of indicators of the existing level of students' preparedness for tolerant relationships, as well as organization of training sessions making it possible to achieve positive results in the deliberate choice of values of positive tolerance.
\end{abstract}

Keywords: tolerance; methods of diagnostics of the level of students' readiness for tolerant relationships; techniques of psychological and pedagogical support of tolerant behavior of a student's personality; strategy of interaction.

\section{Introduction}

Currently a wide variety of educational programs aimed at developing professionally and socially relevant qualities of a student's personality are designed and implemented in higher education institutions. In this regard, it should be noted that along with the need for developing in-depth professional competence of future professionals one should not underestimate the significance of the task of developing social competences, reflecting the level of general humanitarian culture and the presence of active citizenship. One of the indicators of the social focus of an individual is the urge of each of us to feel oneself a citizen both of one's homeland and of the world. That draws our attention to the concept of tolerance, which can be briefly characterized as a person's ability to harmonize the understanding of one's own national identity with respect for many other national cultural traditions, the source of which is one's urge to respect different opinions, ways of thinking and cultural patterns of behavior.

As for the sources helping to articulate the concept of tolerance in the most complete way, we should, first of all, address the well-known international instrument - Declaration of principles on tolerance: "Tolerance is respect, acceptance and appreciation of the rich diversity of our world's cultures, our forms of expression and ways of being human." [Declaration of principles on tolerance. UNESCO, 1995] [1]. International instruments of this kind contribute to the consolidation of countries on the basis of universal human values and identify the key ideological guidelines for the development of the world's education systems. Emphasizing the role of ideology in this case, V.I Andreyev notes that "...Alongside with education, the ideological influence sets the vector of development and is able to purposefully control and adjust the process of development, self-development and behavior of an individual and of the population of the whole country" [Andreev, 2013] [2].

There is no doubt that the ideology of tolerance may be included among relevant values that define our understanding of a cultural, civilized human of the twenty-first century. It is understandable, therefore, that researchers in recent years pay much attention to the problems of tolerance. Let us return to the essence of the problem under consideration and recall that in the context of the Russian rhetoric the concept of "toleration" was traditionally synonymous with the concept of an absolute value. It was a postulate in religious teachings and in the philosophical and ethical theories (L.N. Tolstoy, N.K. Roerich). This concept was equally important in humanistic and existential psychology, 
namely: in the works by K. Rogers, G. Allport, V. Frankl, A.G. Asmolov, etc. [Kleptsova, 2004] [3]. Currently researchers more often use the concept of "tolerance". Among the foreign authors who could draw attention to the problem, we should mention the works by G. Allport. First, the author emphasizes that tolerance is an essential personal characteristic of an individual living in a democratic society. Secondly, he specifies a certain set of qualities that are essential for a tolerant person, among which he mentions the willingness to understand one's position in relation to others; responsibility, sense of humor, independence, capability for empathy, benevolence, etc. [Allport, 1954) [4].

Among domestic authors, who led the the practical application development of the ideology of tolerant consciousness in the educational institutions, we should mention works by A.G. Asmolov and G.U. Soldatova. Relying on the opinion of these researchers, the most complete definition of the concept of "tolerance" is one that includes: respect for and recognition of equality, rejection of domination and violence, recognition of multidimensionality and diversity of human culture, norms, beliefs, refusal of reduction of this diversity to uniformity or to the dominance of any single point of view [Soldatova, 1998] [5]. The key characteristic of the given problem is that it is also studied by the researchers of various scientific profile: philosophy, psychology, history, sociology and pedagogics. Moreover, in the long run, the problem can be effectively resolved only at the level of the integrated, multidisciplinary research. In particular, the analysis of opinion polls, aimed at the studying of the phenomenon of "tolerance" among teenagers and young people and conducting special socio-cultural research with reference to the features of Russia as a multicultural and multireligious country, is of primary importance at the level of actualization of the problem. In this regard, an important contribution to solving these scientific problems was made by the staff of the Centre of Sociology of the Russian Academy of Education within the framework of the implementation of the Federal special purpose program for "The formation of attitudes of tolerant consciousness and prevention of extremism in the Russian society (2001-2005)". This research center primarily applied interdisciplinary approaches to the study of value orientations and world view of Russia's young generation, while recognizing that an integrated approach should be applied not only at the level of "relationship of ideas", but also at the level of methodological procedures, research programs and projects [Sobkina, 2006] [6]. The research in the field of tolerance organized by the Centre of Sociology, was published in international journals and assessed by experts [Sobkin, 2003] [7], [Sobkin, 2002] [8].

In terms of reforming the Russian education at the present stage on the basis of competency-based approach, we can also identify relevant goals of teaching values of tolerance to students of higher education institutions. That can be confirmed by the findings of a study conducted by A.A. Verbitsky, who carried out the analysis of this key approach and proposed to distinguish between objective and subjective conditions of its implementation in the process of ensuring quality of vocational training. This is explained as follows: "The objective conditions will be referred to as competencies and understood as the scope of activity of a specialist, his rights, duties and responsibilities defined in various official documents: laws, directives, decrees, orders, regulations, instructions, etc. Subjective conditions, i.e. competences, include the existing system of responsible relationships and attitudes toward the world, others and oneself, professional motivations, professionally important qualities of a specialist's personality, his psychophysiological characteristics, abilities, knowledge, abilities, skills, etc." [Verbitsky, 2013] [9].

All this, in our view, is a strong argument in favor of the assumption that educational work with students necessarily includes, in particular, at the competency level, a special program for the development of an individual's culture of tolerance.

\section{Methodology}

Each new educational project requires dedicated development of the criteria for the evaluation of actual achievements and the choice of appropriate technologies, making it possible to achieve the expected results. In our project we used the following basic methods, which are well-known in the international practice and at the same time are adjusted with regard to the characteristics of the Russian professional education [Mukhametzyanova, 2011] [10]. These methods include tests; content analysis; a cycle of context trainings, ideologically and methodologically close to the method of CASE STUDIES; projective techniques; correlative and semantic methodology; mathematical methods, such as using Student's t-criterion. The questionnaire for the analysis of group concepts of tolerance was developed by A.F. Korniyenko [Korniyenko, 2000] [11].

\section{Literature Review}

The experimental part of our study, carried out on the basis of Kazan Federal University (2012-2014), had three tasks: organization of analytical and diagnostic procedures for studying the initial level of tolerance qualities among students of 
different institutes and faculties of the University (1); approbation in the experimental student groups of the educational and developmental training course aimed at developing and enhancing the culture of tolerance among the students of these groups (2); evaluation of the effectiveness of training and development of recommendations (3).

Addressing the first task was associated with the development of a package of diagnostic tools aimed at studying the level of preparedness and ability of students to engage in tolerant relationships at different stages of the experiment (initial, formative, resulting and analytical). For this purpose we used a questionnaire entitled "Qualities of a tolerant personality". The sample included 325 students studying in various institutes of Kazan Federal University. This procedure makes it possible to identify at the initial stage the level of existing culture of tolerant relationships and preparedness for these relationships; the content of students' values concerning the concept of "tolerance". The questionnaire included fifteen qualities which in the aggregate reflect a set of qualities and conditions of personality determining its tolerance or intolerance. The choice of preferences included the following qualities and properties: tolerance to negative attitude (1); restraint of emotions (2); anxiety (3); tranquility (4); pliability (5); propensity for self-sacrifice (6); respect for people of another nationality (7); independence of judgment and action (8); propensity to impose one's opinion on others(9); propensity to assert one's beliefs (10); implacability on one's disadvantages (11); ability to understand a different point of view (12); ability to forgive mistakes and misconceptions (13); respect for other tastes and customs (14); benevolence in relationships (15).

Based on the results of the questionnaire survey conducted at the original stage of the experimental work, we built a rating of the students' value choice, reflecting the essence of group concepts concerning understanding of tolerant qualities of a personality, which is presented in the following table (dominant positions are highlighted with a marker).

Table: Rating of students' values related to the interpretation of the concept of "tolerance"

$\begin{array}{clcc}\text { No. } & \text { Quality } & \text { Average Value } & \text { Rating } \\ 1 & \text { Tolerance to negative attitude } & 6.8 & 9 \\ 2 & \text { Restraint of emotions } & 7.2 & 8 \\ 3 & \text { Anxiety } & 12.4 & 2 \\ 4 & \text { Tranquility } & 5.7 & 10 \\ 5 & \text { Pliability } & 8.1 & 7 \\ 6 & \text { Propensity for self-sacrifice } & 9.7 & 6 \\ 7 & \text { Respect for people of another nationality } & 5.3 & 12 \\ 8 & \text { Independence of judgment and action } & 9.8 & 5 \\ 9 & \text { Propensity to impose one's opinion on other people } & 14.1 & 1 \\ 10 & \text { Propensity to assert one's beliefs } & 11.8 & 3 \\ 11 & \text { Implacability on one's disadvantages } & 10.4 & 4 \\ 12 & \text { Ability to understand a different point of view } & 4.2 & 14.5 \\ 13 & \text { Ability to forgive mistakes and misconceptions } & 4.7 & 13 \\ 14 & \text { Respect for other tastes and customs } & 4.2 & 14.5 \\ 15 & \text { Benevolence in relationships } & 5.6 & 11\end{array}$

In the table we can see that at the initial stage of the experiment, the students most often associated the concept of "tolerance" with the following qualities: ability to understand a different point of view; respect for other tastes and customs; ability to forgive mistakes and misconceptions of others; benevolence in relationships; respect for people of another nationality. Such qualities as propensity to impose one's opinion on other people; anxiety; propensity to assert one's beliefs; implacability on one's disadvantages, bear little relation to the concept of tolerance. Such qualities as tolerance to negative attitude of others; restraint of emotions; pliability; the propensity for self-sacrifice; independence of judgment and action, have average importance in the views of the given sample on the concept of "tolerance" and are little different from each other.

The rating of the group concepts of the content of the concept of "tolerance" is also represented in the form of a chart: 


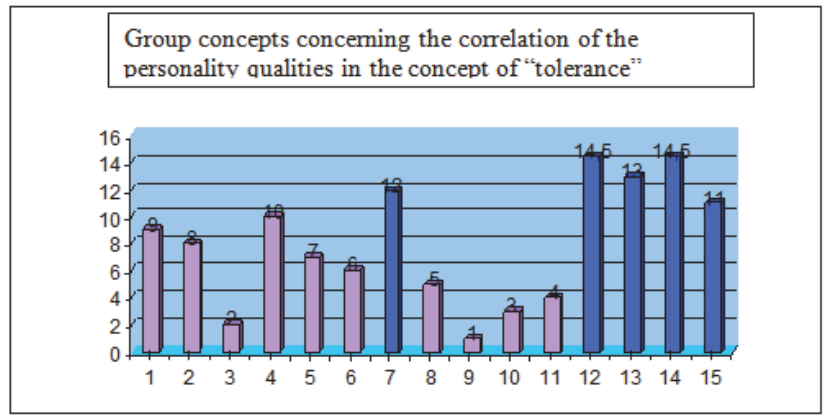

Figure 1. The chart of the rating of group concepts concerning the content of the concept of "tolerance"

A detailed comparative analysis of the group assessment and self-assessment of students shows that the students rate high (more than 8 points) such qualities as: ability to understand a different point of view; ability to forgive mistakes and misconceptions of others; respect for other tastes and customs; benevolence in relationships. It should be noted that selfassessment usually exceeds the group assessment. As for the quality of respect for people of another nationality, there is the greatest spread of values, i.e., the presence of this quality in the students' assessments is unstable.

The difference in regard to qualities between groups of tolerant and intolerant students was also diagnosed. A comparative assessment of the average values of "tolerant" and "intolerant" students shows that reference understanding of studied qualities among tolerant respondents is higher than that of intolerant respondents. The exceptions are the qualities of anxiety, propensity to impose one's opinion on others and independence of judgment and action. In regard to these qualities, the assessment of the tolerant students is little different from that of intolerant students. These trends were checked for validity using Student's t-criterion. The presented data are common for all institutes and faculties, where the experimental research was carried out.

All the obtained data was carefully analyzed, and on their basis we set tasks of organizing special sessions for psychological and pedagogical correction. It was the stage of solving the second task of our experimental research, which was to conduct a cycle of educational and developmental training sessions in the experimental groups of students. Their main aim was to develop and enhance a culture of tolerance among the students of these groups. We also proceeded from the assumption that during practical training there is an opportunity to build a more complete picture of correlation between the students' declared positions in relation to the understanding of the values of tolerance and the actual implementation of these values in behavioral reactions in response to the proposed problematic situation. That was the aim of the special program of psychological and pedagogical training. The task of the program was to improve the culture of tolerance through the development of atmosphere of trust and emotional comfort in a group for each participant and reducing psychological distance between group members. The program was scheduled for three days.

On the first day the psycho-gymnastic exercises were performed [Khryashcheva, 2004] [12], aiming at changing the condition of each participant of the training. At the same time the task of forming a group as an integral community was also solved.

The task of the second day was the involvement of the students in the processes of self-cognition and selfdisclosure, as well as the development of self-esteem and respect for the personal dignity of other group members. The exercises included in the program of this day were aimed at the promotion of self-disclosure and obtaining information on the other group members, as well as the discovery of previously unknown interesting qualities in other team members, finding some common ground with them, developing skills of communicative competence [Sidorenko, 2008] [13], as well as the ability to listen to and understand others.

The task of the third day was to improve the group cohesion. To accomplish this, we used art therapy exercises [Oaklander, 1989] [14] and a method of group picture, which help to form a sense of belonging to a group [Schottenloher, 2001] [15] and a sense of respect for oneself and others. Role-playing [Sukhovershina, Tikhomirnova, \& Skoromnaya, 2006] [16], [Newstron, \& Scannel, 1996] [17] made it possible for group members to get experience of cooperation and interaction in a team, develop the ability to engage in a dialogue and enhance tolerance between the participants [Thorne, \& Mackey, 2001] [18].

In the psychological and pedagogical activities, aimed at the development of the culture of tolerance, took part students of the Institute of international relations, history and oriental studies; Institute of language and intercultural 
communication; Institute of computational mathematics and technology of Kazan (Volga region) Federal University. Evaluation of the effectiveness of the conducted training sessions made it possible to identify the following progressive personality changes. In the groups of students who took part in training sessions, the interest in the problem of tolerant communication increased by $40 \%$, and the awareness of the concept of tolerance increased by $50 \%$. An important result of these training sessions was also the improvement of students' culture of willingness for a dialogue in the process of communication, which was reflected in the improvement of relationships in the group. In the process of individual counseling the students received necessary psychological support and assistance. Students show a positive attitude towards the conducted training sessions and always look forward to the following sessions.

\section{Conclusion}

While evaluating the results obtained in the management of processes of entrenchment tolerant orientation of a student's personality, it should be noted that the main emphasis must be placed on the values of the teachers of the University. The main goal which is to be achieved by following the ideas of tolerance is improvement of relationship climate within the community of teachers and students. The main sign of the effectiveness of the program in this regard is the creation of the space of interaction and mutual understanding of students and teachers at the University, where the main standard is collaboration and co-management. That's what we call development of the strategy of cooperation in the educational space of the higher education institution. The general movement in this direction can be expressed in the following indications of interaction:

- cooperation in dealing with all sorts of creative (educational, scientific, and educational) tasks;

- $\quad$ willingness for dialogue; striving for mutual understanding;

- mutual support, setting the stage for creative activities;

- active attitude, showing interest in educational projects and creative development within the framework of educational programs;

- ability and willingness of teachers and student activists to divide the authority for the benefit of the common cause.

The careful analytical and diagnostic work on all the above positions based on a specially designed package of diagnostic tools, makes it possible to evaluate deeply and comprehensively the real results in regard to the implementation of the strategy of cooperation, which we consider to be a basis for consolidating values of tolerance in the University community as a whole.

\section{Results}

In general, our experience and the results of the conducted experimental research confirm that the programs of psychological and pedagogical support which are implemented by faculties/institutes of humanities and those of natural sciences, contribute to significant improvement of psychological atmosphere and human relationships, assimilation of norms of tolerant behavior in the system of different types of student communities - at the level of an academic group, of an individual department (faculty, institute), as well as at the level of the student community of the University as a whole. It is important to note that the strategy for interaction between teachers and students in key areas (education, science, informal communication) becomes very real.

\section{References}

Declaration of principles on tolerance. (1995). UNESCO, Paris.

Andreev, V. (2013). The concept, laws and ideology of the guaranteed quality of education on the basis of creative self-development (akmeoqualitology of education). Kazan: The centre of innovative technologies.

Kleptsova, E. (2004). Psychology and pedagogics of tolerance: A tutorial for students of further vocational pedagogical education. Moscow: Academic Project.

Allport, G. (1954). Nature of Prejudice. Cambridge, MA: Addison-Wesley.

Soldatova, K. (1998). Ethnic tension. Moscow: Smysl.

Sobkin, V. (2006). Sociology of education: Discussions, technologies, methods: Works on the sociology of education. Vol. XI, Issue XVIII. Moscow: The Centre of the sociology of education of the Russian Academy of Education.

Sobkin, V. (2003). The Formation of National Identity and Value Orientations Among Jewish Teenagers in Russia. From Pacesetters to Dropouts. Post-Soviet Youth in Comparative Perspective. Lanham, New York, Oxford: University Press of America.

Sobkin, V., \& Vladimirov, A. (2002). Attitudes of Jewish and Russian University Students about Becoming Parents: A Comparative 
Study. Jews in Eastern Europe. The Hebrew University of Jerusalem, The Avraham Herman Institute of Contemporary Jewry. Verbitsky, A., \& Larionova, O. (2013). Personality and competency-based approaches in education: problems of integration. Moscow: Logos.

Mukhametzyanova, G. (2011). Methodology and technology of experimental work in the pedagogics of professional education: Multiauthor monograph. Kazan: Idel-Press.

Korniyenko, A. (2000). Theory and practice of psychological research: Tutorial. Kazan: Kazan Pedagogical University.

Khryashcheva, N. (2004). Psychogymnastics in training. St. Petersburg: Rech.

Sidorenko, E. (2008). Training of communication competence. St. Petersburg: Rech.

Oaklander, V. (1989, January 1). Windows to our children: A Gestalt Therapy Approach to Children and Adolescents. Gestalt Journal Press, 348.

Schottenloher, G. (2001). Drawing and image in Gestalt therapy. St. Petersburg: Pirozhkov Publishing House.

Sukhovershina, Yu., Tikhomirnova, E., \& Skoromnaya, Yu. (2006). Business (professional) communication training. Moscow: Academic Project.

Newstron, J., \& Scannel, E. (1996). The big book of Business games. McGraw-Hill Companies, Inc. ISBN 0-07-046476-6.

Thorne, K., \& Mackey, D. (2001). Everything you ever needed to know about training; $2^{\text {nd }}$ edition. Kogan Page. ISBN 074943463. 